\title{
A Inclusão Digital no Contexto Social da Educação de Jovens e Adultos: Um Estudo Exploratório nas Escolas de Macau - RN
}

\author{
Victória G. da Silva Alves ${ }^{1}$, João Helis Bernardo ${ }^{1}$, Maria Clara L. de Lemos ${ }^{1}$ \\ ${ }^{1}$ Instituto Federal do Rio Grande do Norte (IFRN) \\ Macau - RN - Brasil \\ victoria.gabrielledescolar.ifrn.edu.br, \\ \{joao.helis, clara.lucena\} @ifrn.edu.br
}

\begin{abstract}
Computerization is a basic requirement for individuals belonging to today's society. However, Brazil still has a large number of people on the margins of digital inclusion, especially in the context of Youth and Adults. In this sense, this research aims to analyze whether the schools in Macau - RN, which work with Youth and Adult Education (EJA), digitally include their students and whether their teaching staff is composed of professionals with the necessary training to act in that process. Interviews and questionnaires were applied with students and teachers from schools that work with EJA in the municipality. The results showed that schools do not have technologically trained teachers, in addition to the absence of computer labs.
\end{abstract}

Resumo. A informatização é um requisito básico para indivíduos pertencentes à sociedade atual. Contudo, o Brasil ainda tem um grande número de pessoas à margem da inclusão digital, especialmente no contexto de Jovens e Adultos. Nesse sentido, esta pesquisa tem o objetivo de analisar se as escolas de Macau-RN, que trabalham com a Educação de Jovens e Adultos (EJA), incluem digitalmente seus alunos e se o seu corpo docente é composto por profissionais com formação necessária para agirem nesse processo. Aplicaram-se entrevistas e questionários com alunos e professores das escolas que trabalham com a EJA no municipio. Os resultados mostraram que as escolas não têm professores tecnologicamente capacitados, além da ausência de laboratórios de informática.

\section{Introdução}

Assim como ler e escrever, a informatização tem se tornado um dos conhecimentos principais da educação básica por ser essencial para a realização de tarefas simples do cotidiano. No entanto, conforme o Instituto Brasileiro de Geografia e Estatística (IBGE, 2018), o Brasil ainda tem um expressivo número de 11,8 milhões de analfabetos, o que corresponde a 7,2\% da população de 15 anos ou mais. Esses dados são um indicativo de que, para a efetivação da alfabetização e para a introdução de Jovens e Adultos na educação brasileira, as políticas públicas que as promovem devem ser revisadas. Como uma política de reintrodução de jovens e adultos na educação, ou até mesmo na inicialização destes nesse contexto, a modalidade de ensino Educação de Jovens e Adultos (EJA) destaca-se.

A Inclusão digital "se refere à democratização das tecnologias da informação, com a intenção de garantir o acesso de todas as pessoas, independentemente da condição econômica" [Cunha \& Gurgel, 2016, p. 418]. Promover o acesso e a utilização dessas novas tecnologias, trazendo significado à vida do indivíduo, independente da sua condição e idade, possibilitará que este desenvolva habilidades e competências para uma melhor integração na sociedade. Sendo assim, a inclusão digital na EJA se torna 
extremamente necessária e relevante. Contudo, ainda há poucos trabalhos que lidem diretamente com a inclusão digital nesta modalidade de ensino, especialmente na região da Costa Branca do estado do Rio Grande do Norte, limitando ações governamentais que se relacionem com o objetivo de retirar os alunos da categoria de exclusos digitais.

Nesse viés, o objetivo desta pesquisa é analisar se as escolas de Macau - RN, que trabalham com a Educação de Jovens e Adultos, incluem digitalmente seus alunos e se o corpo docente dessas escolas é composto por profissionais com formação necessária para agirem ativamente nesse processo. Além disso, o trabalho pretende analisar se as escolas possuem infraestrutura necessária para lidar com a utilização das novas tecnologias de informação e comunicação nas suas atividades curriculares cotidianas.

\section{Inclusão Digital na Educação de Jovens e Adultos}

Conforme Castells (1999, p. 43), "a tecnologia é a sociedade, e a sociedade não pode ser compreendida ou representada sem as suas ferramentas tecnológicas". Logo, a tecnologia é inerente à sociedade, faz parte de sua trajetória. Ela é, também, um dos recursos que diferenciam a humanidade dos outros seres vivos, pois somos capazes de criar ferramentas tecnológicas que auxiliam na compreensão de nós mesmos, além de transformar culturas, valores e costumes. Segundo Castells (1999, p. 44),

A habilidade ou inabilidade de as sociedades dominarem a tecnologia, e em especial, aquelas tecnologias que são estrategicamente decisivas em cada período histórico, traça seu destino a ponto de podermos dizer que, embora não determine a evolução histórica e a transformação social, a tecnologia (ou sua falta) incorpora a capacidade de transformação das sociedades, bem como o uso que as sociedades, sempre em um processo conflituoso, decidem dar ao seu potencial tecnológico.

Não basta que se tenha todas as ferramentas materiais (e. g., computadores) para sermos incluídos digitalmente, mas é necessário estarmos em condições e participarmos dos processos evolutivos das tecnologias. É necessário que todos os indivíduos tenham acesso as tecnologias para que não fiquem à margem da sociedade [Lévy 2000].

A inclusão digital é um avanço da informática, logo, se os indivíduos e a sociedade não se adaptarem às mudanças que as tecnologias vêm impondo nas instituições, serão excluídos desse processo [Tavarayama \& Silva \& Martins, 2012]. Incluir digitalmente alunos da EJA lhes garante maiores possibilidades de inserção social. Conforme Joaquim (2015), há um enorme número de adultos que não foram incluídos na cultura digital e isso se deve ao fato de que os adultos são entendidos como coadjuvantes da inclusão digital.

Um dos fatores que conduzem um jovem ou adulto a reingressar ou iniciar nos estudos são as exigências acadêmicas contidas no atual cenário do mercado de trabalho, que transformou também numa exigência básica (além de ler e escrever) o domínio e as habilidades na área da informática. Contudo, se o nível de alfabetizados entre o grupo de jovens e adultos é aquém das expectativas, esperar que estes se tornem ainda mais deslocados quando o assunto é inclusão digital.

É importante que todos, em qualquer faixa etária e classe social, tenham acesso à educação. A EJA, além de reintroduzir jovens e adultos no ambiente escolar, também apresenta pela primeira vez o mundo da educação para aqueles que nunca tiveram acesso. Conforme Limberger et al. (2015, p. 2), ela "tem amparo legal na Lei de Diretrizes e Bases da Educação Nacional, no 9.394/96, na qual consta no Título V, Capítulo II, Seção $\mathrm{V}$, dois artigos relacionados especificamente a essa modalidade". Apesar disso, é nessa 
modalidade de ensino que se torna mais difícil implementar a inclusão digital visto que muitas dessas pessoas não sabem ler e escrever [Franco, 2003].

A inclusão digital na Educação de Jovens e Adultos atua como mediadora e tem por finalidade aproximar o discente das tecnologias atuais, gerando um novo âmbito para esse aluno. Além disso, promove a introdução do indivíduo na sociedade e o torna habilitado para ingressar no mercado do trabalho.

\section{Metodologia}

A abordagem metodológica desta pesquisa se dá a partir da utilização de métodos mistos, considerando que os instrumentos utilizados para o levantamento de dados passaram por análises de cunho qualitativo e quantitativo [Shorten \& Smith 2017]. Com isso, a escolha do método adotado é justificada pela compreensão de que, dessa forma, a validação das informações aumenta consideravelmente, uma vez que os dados podem ser coletados e analisados sob diferentes perspectivas. O objetivo é identificar o maior número de elementos específicos possíveis com base na experiência dos que contemplam a modalidade de ensino EJA.

\subsection{Levantamento de Dados}

Este estudo exploratório se tratou de uma investigação sobre a inclusão digital em três das cinco escolas que utilizam a Educação de Jovens e Adultos (EJA) em Macau - RN. Entrevistas semiestruturadas foram realizadas com quatro professores e um gestor, seguindo uma sequência de questões para guiar a entrevista. Os professores selecionados foram os que estavam presentes nos respectivos dias de visita.

Para a coleta de dados com alunos, utilizaram-se questionários com questões objetivas e descritivas. A aplicação dos questionários aconteceu do dia 01/10/2019 ao dia $31 / 10 / 2019$, dias nos quais a primeira autora fez visitas diárias às escolas investigadas. Ao todo, foram distribuídos 50 questionários, no entanto, nesses dias, somente 16 alunos participaram ativamente das aulas e responderam ao questionário, além de uma pequena minoria de três estudantes, que não se disponibilizaram a responder, atitude que foi justificada por não se sentirem à vontade. Esse número sugere ainda que, do total de alunos matriculados, poucos participam de forma efetiva das aulas, apontando para um problema preocupante relacionado ao alto índice de evasão.

Ainda, algumas técnicas de observação foram utilizadas com o objetivo de ter uma melhor compreensão do que acontece com relação à inclusão digital na Educação de Jovens e Adultos nas respectivas escolas da cidade.

\subsection{Análise de dados}

Para a interpretação de dados, o método utilizado foi o de análise de conteúdo, que, na definição de Bardin (1977), trata-se de um conjunto de técnicas de análise das comunicações de indicadores, quantitativos ou não, que permitam a inferência de conhecimentos relativos às condições de produção/recepção das mensagens.

A análise do conteúdo das entrevistas e questões abertas foi realizada por meio da Análise Categorial, que possibilita o agrupamento dos textos semanticamente correlacionados a partir de categorias. Essa se mostrou uma boa opção em se tratando de estudos que buscam compreender as opiniões, valores e atitudes de indivíduos sociais. 
A metodologia desta pesquisa foi organizada em concordância com a proposta de sistematização do método de Análise de Conteúdo Temático-Categorial, elaborado por Oliveira (2008), estruturada nas seguintes etapas: (i) Preparação das informações; (ii) Transformação do conteúdo em unidades de registro (UR); (iii) Classificação das Unidades de Registro em Temas; (iv) Classificação das Unidades de Registro em Categorias; e (v) Descrição e Interpretação dos dados.

\section{Resultados e Discussões}

Esta pesquisa realizou um estudo exploratório para analisar a inclusão digital no contexto social da Educação de Jovens e Adultos (EJA) nas escolas da rede pública de Macau/RN. Foram aplicados questionários e entrevistas em três das cinco escolas que utilizam a modalidade de ensino EJA na cidade. Do total, $100 \%$ (5/5) das escolas que utilizam o modelo de ensino EJA no município são da rede pública municipal.

Para a realização da pesquisa, 16 discentes de três instituições que utilizam a modalidade de ensino EJA contribuíram com o estudo ao responder o questionário proposto pelos autores ${ }^{1}$. De acordo com os dados coletados, $62 \%$ dos discentes têm entre 15 e 30 anos; $25 \%$ entre 30 e 50 anos; $6 \%$ entre 50 e 60 anos ou mais; e $6 \%$ não declararam a idade. Os números apresentados não condizem com a realidade nacional, já que, segundo o IBGE (2018), o analfabetismo no Brasil atinge em maior escala grupos populacionais mais velhos, como é possível observar a partir da Figura 01.

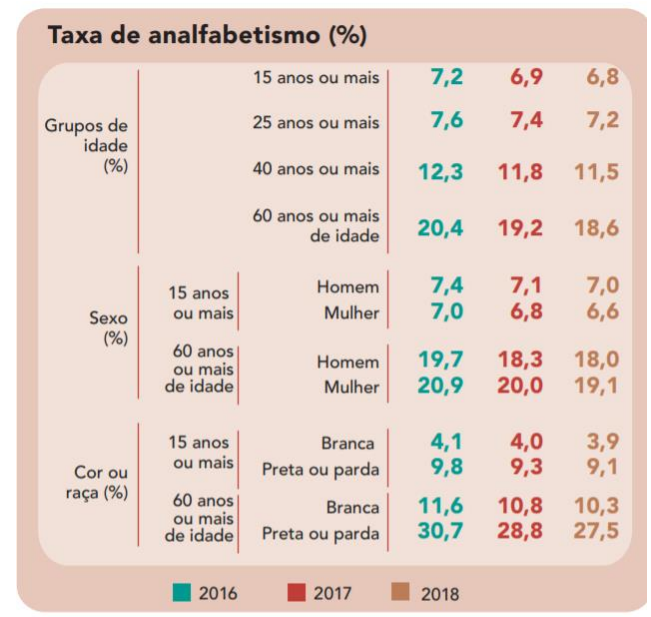

Figura 01. Taxa de analfabetismo do Brasil nos últimos três anos. Fonte: IBGE, Diretoria de Pesquisas, Coordenação de Trabalho e Rendimento, Pesquisa Nacional por Amostra de Domicílios Contínua 2016-2018.

Ao analisar a quantidade de discentes por sexo, notou-se que há predominância de homens em relação às mulheres, que representam apenas $25 \%$ dos alunos entrevistados (4/16). 58,3\% dos discentes do sexo masculino pertencem ao grupo populacional que apresenta entre 15 e 30 anos; $25 \%$ entre 30 e 50 anos; $8,3 \%$ entre 50 e 60 anos ou mais; e 8,3\% não declararam a idade (ver Gráfico 01). A realidade brasileira corrobora esses dados pois, de acordo com o IBGE (2018), a taxa de analfabetismo entre homens e mulheres aponta superioridade para brasileiros do sexo masculino com 15 anos ou mais. Os números se invertem quando se trata de pessoas com 60 anos ou mais (ver Figura 01).

\footnotetext{
${ }^{1}$ Apêndices da Pesquisa. Disponível em: <https://bit.ly/3frs1vq>. 2020.
} 
No Brasil, a taxa de analfabetismo entre brancos, negros ou pardos é significativamente diferente (IBGE, 2018), conforme Figura 01. Os dados colhidos nas três instituições de ensino confirmam a realidade do país. Um quantitativo de $56,2 \%$ dos discentes participantes da pesquisa é negro ou pardo; $31,2 \%$ é de etnia branca; e $12,5 \%$ não identificaram a etnia (ver Gráfico 02). Não é de hoje que esses números são observados. Vários autores relatam a superioridade na taxa de analfabetismo para negros ou pardos em relação a brancos e. g. [Rosemberg, Piza, 1996 \& Silva, 2012]. Ou seja, 131 anos após a "abolição" da escravidão, a desigualdade racial é notória em todos os âmbitos da sociedade e "parte significativa dela não é atribuível a nenhuma medida de mérito ou esforço, sendo puramente resultado de discriminações passadas ou presentes" [Theodoro 2008].
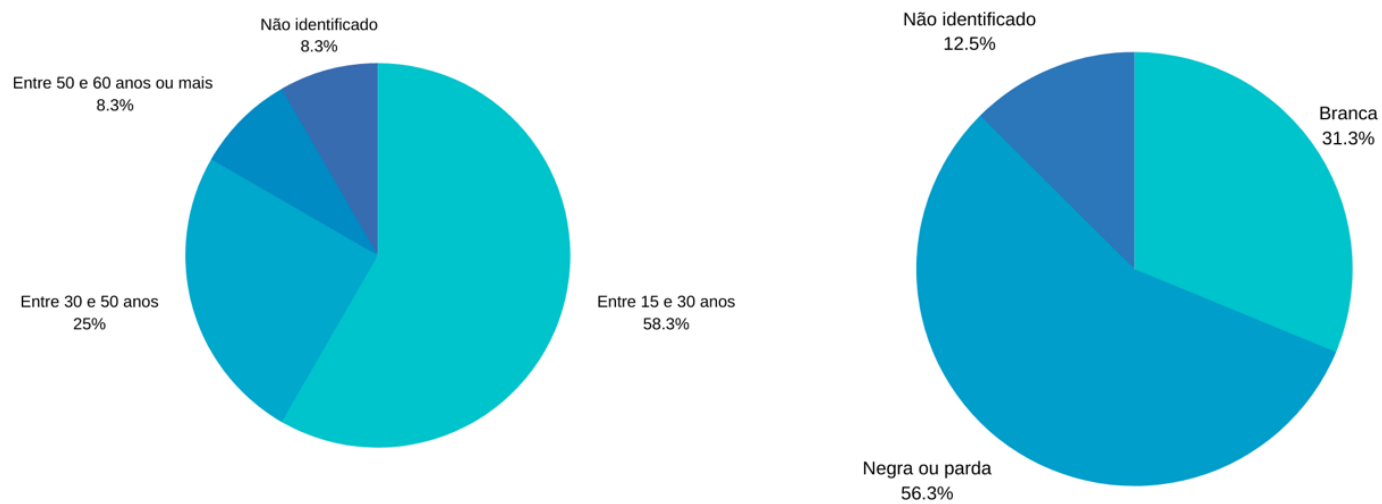

Gráfico 01. Distribuição dos discentes do sexo masculino por faixa etária. Gráfico 02. Comparativo de etnia dos discentes. Fonte: Dados da pesquisa (2019).

Das três escolas investigadas $(66,7 \%, 2 / 3)$, duas não têm laboratórios de informática como parte da sua estrutura. Apenas uma escola possui laboratório e os equipamentos tecnológicos necessários, no entanto, são mantidos em uma sala fechada. Sendo assim, um total de $100 \%$ das escolas (3/3) não utilizam computadores em suas atividades escolares, mesmo apesar de $100 \%$ dos professores e alunos entrevistados concordarem que a inclusão digital é um requisito básico para a realização de atividades escolares, assim como para inserir os alunos no ambiente digital através do uso de tecnologias. É curioso mencionar, também, que mesmo com estrutura (em uma escola), nenhuma das escolas investigadas possui rede de internet. Além disso, um quantitativo de 75\% (3/4) de professores entrevistados alegaram que a secretaria de educação não disponibiliza formação de professores voltada para a inclusão digital na formação de jovens e adultos. Adicionalmente, é importante destacar que nenhum dos professores entrevistados (0/4) possui formação acadêmica na Educação de Jovens e Adultos ou na área de informática. 
Tabela 1. Perfil dos professores entrevistados. Fonte: Dados da pesquisa (2019).

\begin{tabular}{llll}
\hline ID & Sexo & Experiência & Duração da entrevista \\
\hline EN01 & F & 8 & $5 \mathrm{~min}$ \\
EN02 & F & 14 & $10 \mathrm{~min}$ \\
EN03 & F & 16 & $4 \mathrm{~min}$ \\
EN04 & M & 16 & 5 min \\
\hline
\end{tabular}

\subsection{Descrição dos Resultados}

A partir das entrevistas realizadas com os professores, dos questionários aplicados aos alunos das escolas investigadas acerca da inclusão digital na era da informação, bem como a capacitação de discentes, docentes e instituições para a utilização de tecnologias no quesito ensino-aprendizagem, foram identificadas quatro categorias principais de análise: I. Situação atual da modalidade de ensino EJA; II. A importância da inclusão digital na Educação de Jovens e Adultos e os seus benefícios no processo de ensinoaprendizagem; III. Dificuldades para introduzir a inclusão digital na modalidade de ensino EJA; IV. Incentivo aos professores na utilização de tecnologias.

A primeira categoria apresenta relatos sobre a Situação atual da modalidade de ensino EJA. Dentre os temas mais citados pelos professores sobre o assunto, estão: (i) Evasão escolar; (ii) Choque entre realidades; (iii) Forma de nivelar idade-série.

A segunda categoria trata da Importância da inclusão digital na Educação de Jovens e Adultos e os seus benefícios no processo de ensino-aprendizagem, dentre os temas citados pelos professores e alunos, estão: (i) Auxilia na introdução do indivíduo em sociedade; (ii) Influencia no processo de aprendizagem; (iii) Mais acesso à informação; (iv) Outras formas de conhecimento e autonomia; (v) Auxilio no mercado de trabalho atual.

A terceira categoria, Dificuldades para introduzir a inclusão digital na modalidade de ensino EJA, apresenta os seguintes pontos trazidos por professores e alunos que colaboraram com a pesquisa: (i) Falta de laboratórios; (ii) Os laboratórios não funcionam; (iii) Os alunos não possuem prática para manusear tecnologias.

A última categoria se trata do Incentivo aos professores na utilização de tecnologias e apresenta os temas: (i) A secretaria não oferece cursos de formação; e (ii) Não há mais incentivo. Na Tabela 2, a seguir, essas categorias são apresentadas de forma resumida.

Tabela 2. Classificação numérica das Unidades de Registro das entrevistas e questionários. Fonte: Dados da pesquisa (2019).

\begin{tabular}{|l|l|c|}
\hline CATEGORIA DE ANÁLISE & TEMAS & UR's \\
\hline \multirow{3}{*}{$\begin{array}{l}\text { Situação atual da modalidade de } \\
\text { ensino EJA }\end{array}$} & Evasão escolar & 3 \\
\cline { 2 - 3 } & Choque entre realidades & 3 \\
\cline { 2 - 3 } & Nivelamento idade-série & 3 \\
\hline \multirow{3}{*}{$\begin{array}{l}\text { A importância da inclusão digital } \\
\text { na Educação de Jovens e Adultos e } \\
\text { seus benefícios no processo de } \\
\text { ensino-aprendizagem }\end{array}$} & Influência no processo de aprendizagem; & 3 \\
\cline { 2 - 3 } & Mais acesso à informação & 5 \\
\cline { 2 - 3 } & Outras formas de conhecimento e autonomia & 71 \\
\cline { 2 - 3 } & Auxílio no mercado de trabalho & 7 \\
\hline
\end{tabular}




\begin{tabular}{|l|l|c|}
\hline \multirow{2}{*}{$\begin{array}{l}\text { Dificuldades para introduzir a } \\
\text { inclusão digital na modalidade de } \\
\text { ensino EJA }\end{array}$} & Falta de laboratórios & 5 \\
\cline { 2 - 3 } & Os laboratórios não funcionam & 2 \\
\cline { 2 - 3 } & Ausência de prática dos alunos para manuseio de tecnologias & 4 \\
\hline $\begin{array}{l}\text { Incentivo aos professores na } \\
\text { utilização de tecnologias }\end{array}$ & A secretaria não oferece cursos de formação & 4 \\
\cline { 2 - 3 } & Não há mais incentivo & 3 \\
\hline
\end{tabular}

\subsubsection{Situação atual da modalidade de ensino EJA}

Tendo como base os questionários aplicados nas turmas de EJA e as entrevistas feitas aos professores, pode-se depreender que essa modalidade de ensino se encontra em situação de grande evasão escolar. Como exemplo, tem-se o seguinte trecho retirado da entrevista de uma professora com formação em língua inglesa, que falava sobre a evasão na Educação de Jovens e Adultos e os fatores que contribuem para isso.

"Se você olhar nossa folha de frequência, tem 50 alunos em cada turma, e se você olhar, a maior turma é essa (cerca de oito alunos)." (Entrevistada 02).

A entrevistada justifica a desistência dos alunos nas turmas e relata que isso tem a ver com o choque entre idades e a colisão do comportamento entre elas.

“... a gente encontra uma certa dificuldade, porque as pessoas mais idosas reprovam o comportamento dessas mais jovens, porque eles são muito exagerados em comportamentos, então choca. Há um choque. É tanto, que se você observar, não vai encontrar, mas a gente tinha, nessa série, alunos de 70 e poucos anos, mas eles não conseguem se manter, e por causa dessa junção há evasão dos mais velhos." (Entrevistada $02)$.

Colocar em uma mesma sala pessoas de objetivos diferentes, idades diferentes e perspectivas diferentes pode ser um dos fatores que influenciam nos altos índices de evasão em turmas de EJA. Apesar de ser positivo, no ponto de vista de diversificação e de uma possível troca de experiências entre os alunos, os resultados da pesquisa nos mostram que isso não acontece.

Segundo Silva e Arruda (2012), outro grande fator que influencia na desistência dos alunos na EJA é a falta de profissionais sem qualificação adequada para a modalidade de ensino, colaborando, mesmo que indiretamente, para a exclusão social do aluno. Os autores também afirmam que "tem que se usar uma metodologia com conteúdo que despertem a cada um o prazer de estar na sala de aula ou que os motive a permanecerem na escola utilizando uma linguagem simples." [Silva, Arruda 2012, p.115].

\subsubsection{A importância da inclusão digital na Educação de Jovens e Adultos e os seus benefícios no processo de ensino-aprendizagem}

Todos os entrevistados, sem exceções, alegaram que a inclusão digital é essencial para a Educação de Jovens e Adultos. Conforme Lourenço et. al (2012, p. 2), além de ler e escrever, é importante que o indivíduo tenha domínio dos meios digitais pois isso pode garantir uma melhor inserção no mercado de trabalho e no mundo das informações.

"É de grande importância porque é uma coisa mais moderna que a gente traz pra eles "visualizar" e trabalhar em sala de aula, porque só leitura e escrita tem um pouco de alunos, que ainda tem dificuldade, né? $\mathrm{E}$ quando eles veem algo assim mais moderno, por exemplo, os slides ou apresentação com Datashow, eu acharia bem melhor principalmente pra disciplina de biologia né pra ver as imagens.” (Entrevistada 03). 
Ao responder o questionário, um dos discentes apontou alguns benefícios que a inclusão digital traz para um indivíduo:

“estabelecer comunicação, acessar notícias, ver vídeos” (Discente 15).

As respostas dos outros discentes entrevistados encontram-se no mesmo contexto. A maioria alegou os benefícios sobre introduzir o indivíduo no mercado de trabalho e que a inclusão digital anda lado a lado com a autonomia, ou seja, o educando pode, por sua responsabilidade, buscar outras formas de conhecimento e ter mais acesso à informação.

\subsubsection{Dificuldades para introduzir a inclusão digital na modalidade de Ensino EJA}

O primeiro relato coletado vem de um aluno retratando sobre um problema sério, que atrapalha a inclusão digital nas escolas analisadas:

"A internet da escola é bloqueada para os alunos". (Discente 14).

Relembrando o tópico anterior, que trata da importância e dos benefícios da inclusão digital na EJA em virtude de esta possuir informações e formas de conhecimento dentro de uma mesma categoria, é nítido que deixar o aluno à margem disso, excluindoo, enquanto o correto era introduzir o educando nos novos moldes da sociedade, implica em péssimos índices para a modalidade. Isso porque, como dito anteriormente, o método de ensino traz, por vezes, analfabetos digitais e é dever da EJA nivelar isso, bem como introduzir o aluno na Era tecnológica em que vivemos.

Com base nos relatos dos professores, é possível observar que, além de professores sem capacitação para a formação dos alunos na área da informática, as escolas também não possuem a infraestrutura necessária para receber os materiais ou ofertar laboratórios em seu espaço. Quando não é esse o problema, as escolas têm laboratórios como parte da sua estrutura, mas estão em desuso; isso é uma dificuldade que vai além de capacitação de professores para a modalidade, é um impedimento por parte da gestão.

\subsubsection{Incentivo aos professores na utilização de tecnologias}

As seguintes falas referem-se às respostas dos professores quando questionados sobre o incentivo da secretaria de educação na capacitação dos educandos com relação ao uso de tecnologias em salas de aula.

\footnotetext{
"Durante esse tempo que trabalho aqui, nunca foi. Não foi oferecido nenhuma formação". (Entrevistado 01).

"Atualmente, nós estamos sem essa disponibilidade por parte da secretaria. Não que a secretaria não ache importante, mas devido aos fatores, estamos fracassados nessa área". (Entrevistado 04).
}

Os professores relataram não haver formação para inclusão digital voltada à Educação de Jovens e Adultos, sequer em outras áreas. Esse dado é bastante grave visto que as tecnologias vão avançando a todo momento e não caminhar ao lado disso coloca educandos e educadores à margem da sociedade. A secretaria de educação deve olhar com mais atenção para os novos moldes de ensino e atualizar as escolas da rede municipal o quanto antes. Além disso, e principalmente, olhar com mais cuidado para a formação daqueles que formam cidadãos e cidadãs, bem como investir nisso, para que os resultados sejam mais positivos. Isso porque, utilizando como base o relato da Entrevistada 02, o estado está mais preocupado em preparar mão de obra para o mercado do que com o que importa de fato: a educação dos alunos. 


\section{Considerações finais}

Esta pesquisa teve como objetivo principal analisar a inclusão digital oferecida pelas escolas que aplicam a modalidade de ensino EJA na cidade de Macau - RN, observando se os seus docentes têm a formação necessária para trabalhar com essa modalidade de ensino, bem como se as escolas dispõem de infraestrutura apropriada para utilização das novas TICs. Foram aplicados entrevistas e questionários em três escolas da rede municipal da cidade. O trabalho obteve resultados satisfatórios, alinhados aos seus objetivos. Adicionalmente, durante a aplicação da pesquisa, foi possível elencar temas importantes que não estavam estritamente relacionados ao objetivo da pesquisa, a exemplo da evasão escolar na EJA. Contudo, é importante ressaltar que a pesquisa teve limitações reconhecidas pelos autores, a citar:

I) A aplicação de questionários na turma de EJA foi bastante conturbada, tendo em vista a fragilidade da modalidade de ensino. As questões pareciam ser bastante difíceis e os alunos precisavam de auxílio para interpretação, assim como para responder, pois muitos estavam passando pelo processo de alfabetização.

II) São cinco escolas que utilizam o modelo de ensino EJA, no entanto, nesta pesquisa, foram coletados os dados de apenas três. Apesar de a maioria (3/5) das escolas terem sido pesquisadas, as informações sobre as demais escolas, que compreendem $2 / 5$ do total, e que não puderam ser investigadas, poderiam apresentar dados que alterariam os resultados ora alcançados. No entanto, não foi possível, no período de investigação, desenvolver entrevistas nessas instituições em virtude da ausência dos alunos durante as tentativas feitas.

Como mencionado anteriormente, alguns resultados obtidos não estavam intrinsecamente relacionados ao objetivo do trabalho, como por exemplo, a questão da evasão escolar na EJA, fato que possui diversos motivos. A exemplo disso, temos a ação de colocar, em um mesmo ambiente, alunos de idades completamente diferentes. No que diz respeito à capacitação dos professores na formação de Jovens e Adultos, foi possível identificar, a partir das entrevistas realizadas, que nenhum professor tem especialização na modalidade. Esse, dentre outros, é um agente influenciador na fragmentação da EJA e nos seus índices de evasão. A modalidade, portanto, precisa ser reavaliada com urgência ou, do contrário, continuará excluindo seus educandos socialmente.

Por fim, considerando o objetivo proposto pela pesquisa e a partir da análise das escolas, o que acontece atualmente na EJA é uma exclusão digital. Além de trazer modelos de ensino ultrapassados, limitados ao livro didático e que não compactuam com a realidade de uma sociedade moderna, as escolas não possuem estrutura para laboratórios de informática, os professores não possuem formação na área e os alunos têm seus direitos retirados. Por isso, é importante que as instituições governamentais e educacionais trabalhem para propor melhorias na modalidade de ensino EJA como, por exemplo, capacitação obrigatória na formação dos professores para o domínio das novas tecnologias. Caso contrário, teremos educadores e educandos sempre à margem da era da informação em que vivemos. Para trabalhos futuros, sugere-se realizar uma replicação desta pesquisa nos demais municípios do Rio Grande do Norte e do Brasil, a fim de entender como todo o país vem lidando com a inclusão digital no contexto social da Educação de Jovens e Adultos.

\section{Referências}

Bardin. L. (1977) “Análise de Conteúdo”. Lisboa: Editora Edições 70. 
Castells, M. (1999) “A Era da Informação: A Sociedade Em Rede”. Rio de Janeiro: Paz e Terra, v. 1.

Cunha, R.; Gurgel, Rita. (2016) "Práticas de Inclusão Digital na Educação de Jovens e Adultos: Minicurso de Introdução à Informática". In: Anais do Workshop de Informática na Escola. p. 418.

Franco, M. G. (2003) "Inclusão Digital: Uma Proposta na Alfabetização de Jovens e Adultos". In: Anais do Workshop de Informática na Escola. p. 216-225.

IBGE. Instituto Brasileiro De Geografia e Estatística. (2018). "PNAD Contínua, Educação 2018”, https://biblioteca.ibge.gov.br/visualizacao/livros/liv101657_informativo.pdf, Dezembro.

Joaquim, B. dos S. (2015) “O Empoderamento Freireano à Partir da Inclusão Digital na Educação de Jovens e Adultos”. EJA em debate, Florianópolis, v. 4.

Lévy, P. (2000) “Cibercultura”. São Paulo: ed. 2. Editora 34.

Limberger, D. I; Da Cruz, M. E. J. K.; Mergen, C. C. (2015) "Inclusão Digital de Jovens e Adultos em Processo de Alfabetização: Relato de Experiências a Partir de Programa Institucional". Revista de Educação Ciência e Tecnologia, Canoas, v.4, n.1.

Lourenço, É. S. et al. (2012) "Inclusão Digital na Educação de Jovens e Adultos (EJA)". Revista Científica Eletrônica de Pedagogia, Garça, n. 19, ISSN 1678300X.

Oliveira, D. C. de. (2008) "Análise de Conteúdo Temático-categorial: Uma Proposta de Sistematização”. Revista Enfermagem UERJ, v. 16, n. 4, p. 569-576.

Rosemberg, F.; Piza, E. (1996) “Analfabetismo, gênero e raça no Brasil”. Revista USP, n. 28, p. 110-121.

Shorten, Allison; Smith, Joanna. (2017) "Mixed Methods Research: Expanding the Evidence Base".

Silva, T. S. (2012) "Educação e População Negra: Uma Análise da Última Década (1999/2009)". Relações Raciais no Contexto Social, na Educação e na Saúde: Brasil, Cuba, Colômbia e África do Sul. Rio de Janeiro: Quartet.

Silva, G. P.; Arruda, R. A. (2012) "Evasão Escolar de Alunos na Educação de Jovens e Adultos - EJA". Eventos Pedagógicos, v. 3, n. 3, p. 113-120.

Theodoro, M. et al. (2008) "As políticas públicas e a desigualdade racial no Brasil: 120 anos após a abolição”. Brasília: Ipea, p. 69-99.

Tavarayama, R., Freitas, R. C. M., Martins, J. R. (2012) “A Sociedade da Informação: Possibilidades e Desafios". Nucleus, v. 9, n. 1. 